\title{
Presynaptic Melanocortin-4 Receptors on Vagal Afferent Fibers Modulate the Excitability of Rat Nucleus Tractus Solitarius Neurons
}

\author{
Shuxia Wan, ${ }^{2 *}$ Kirsteen N. Browning, ${ }^{1 *}$ F. Holly Coleman, ${ }^{1}$ Gregory Sutton, ${ }^{1}$ Hiyuan Zheng, ${ }^{1}$ Andrew Butler, ${ }^{1}$ \\ Hans-Rudolf Berthoud, ${ }^{1}$ and R. Alberto Travagli ${ }^{1}$ \\ ${ }^{1}$ Pennington Biomedical Research Center, Louisiana State University System, Baton Rouge, Louisiana 70808, and ${ }^{2}$ Key Laboratory of Allergy and Immune- \\ Related Diseases, Department of Physiology, School of Basic Medical Science, Wuhan University, Wuhan 430071, Hubei, China
}

The nucleus tractus solitarius (NTS) integrates visceral sensory signals with information from the forebrain to control homeostatic functions, including food intake. Melanocortin 3/4 receptor (MC3/4R) ligands administered directly to the caudal brainstem powerfully modulate meal size but not frequency, suggesting the enhancement of visceral satiety signals. Using whole-cell recordings from rat brainstem slices, we examined the effects of melanocortin ligands, $\alpha$-melanocyte-stimulating hormone $(\alpha \mathrm{MSH})$ and melanotan II (MTII), on EPSC in NTS neurons. Thirty-two percent of NTS neurons responded to perfusion with MTII or $\alpha$ MSH with either an increase (24\%) or a decrease $(8 \%)$ in the frequency, but not amplitude, of spontaneous EPSCs; the effects of MTII were abolished by pretreatment with SHU9119. After surgical vagal deafferentation, only four of 34 (9\%) NTS neurons responded to MTII with an increase in EPSC frequency. When EPSCs were evoked by electrical stimulation of the tractus solitarius in Krebs' solution with $2.4 \mathrm{mM} \mathrm{Ca}^{2+}{ }_{\mathrm{e}}$, $\alpha \mathrm{MSH}$ and MTII increased the amplitude in six of the 28 neurons tested, decreased amplitude in 14 with no effect in the remaining eight neurons. In four of six neurons unresponsive to MTII, decreasing $\mathrm{Ca}^{2+}{ }_{\mathrm{e}}$ levels to $1.5 \mathrm{~mm}$ uncovered an excitatory effect of MTII on EPSC amplitude. Reverse transcription-PCR analysis revealed the presence of MC4R, but not MC3R, in nodose ganglia. These results show that MC4R signaling leads mainly to presynaptic modulation of glutamatergic synaptic transmission and suggest that melanocortinergic-induced decrease of food intake may occur via enhancement of vagal afferent satiation signals from the gastrointestinal tract.

Key words: brainstem; vagus; electrophysiology; $\alpha \mathrm{MSH}$; MTII; melanocortin

\section{Introduction}

Food intake is the product of meal size and frequency and is an important determinant of overall energy balance, because hyperphagia is thought to play a significant role in the current obesity epidemic. Humans typically eat a small number of specified meals per day; therefore, controlling meal size is an effective strategy to limit total energy intake.

The caudal brainstem plays a pivotal role in controlling meal size, because it receives direct neural and humoral feedback signals from the gut (Grill and Kaplan, 2002; Berthoud, 2004; Travagli et al., 2006). Satiation signals such as gastric distention or nutrients in the intestine reach the nucleus tractus solitarius (NTS) via vagal afferent fibers or circulating hormones. NTS neurons respond, principally, with activation of glutamatergic vagal inputs (Fraser et al., 1995; Willing and Berthoud, 1997;

Received Dec. 6, 2007; revised March 10, 2008; accepted March 31, 2008.

This work was supported by National Institutes of Health Grants DK 55530 and 47348. We thank Cesare M. Travagli and W. Nairn Browning for support and encouragement.

*K.N.B. and S.W. contributed equally to this work.

Correspondence should be addressed to Dr. R. Alberto Travagli, Neuroscience, Pennington Biomedical Research Center, Louisiana State University System, 6400 Perkins Road, Baton Rouge, LA 70808. E-mail: alberto.travagli@pbrc.edu.

DOI:10.1523/JNEUROSCI.5398-07.2008

Copyright $\odot 2008$ Society for Neuroscience $\quad$ 0270-6474/08/284957-10\$15.00/0
Rinaman et al., 1998; Berthoud et al., 2001; Emond et al., 2001; Baptista et al., 2005a), resulting in the reduction of meal size (Zheng et al., 1999; Treece et al., 2000; Covasa et al., 2004a; Gillespie et al., 2005).

NTS neurons have reciprocal connections with higher CNS centers and integrate signals related to cognitive, emotional, and rewarding influences. Combined with visceral-related information, this contributes to homeostasis in general and control of energy balance and body weight in particular.

A prominent integrative role in energy balance control is played by the central melanocortin system, which comprises hypothalamic and brainstem proopiomelanocortin (POMC) neurons (Palkovits et al., 1987; Appleyard et al., 2005; Cone, 2005). Release of $\alpha$-melanocyte-stimulating hormone ( $\alpha \mathrm{MSH})$ from terminals of POMC neurons modulates food intake and energy balance through activation of the melanocortin- 3 and -4 receptors (MC3R and MC4R, respectively).

We have shown that a small percentage of hypothalamic POMC neurons project to the brainstem (Zheng et al., 2005), reinforcing the possibility that descending hypothalamic melanocortinergic projections play a role in the control of food intake via brainstem vagal circuits. Indeed, $\alpha \mathrm{MSH}$ as well as MC3/4R have been detected in the brainstem (Joseph et al., 1985; Palkovits et al., 1987; Bronstein et al., 1992; Kishi et al., 2003; Liu et al., 
2003). More recently, activation of brainstem MC4R has been shown to reduce meal size (Grill et al., 1998; Williams et al., 2000; Fan et al., 2004; Zheng et al., 2005) without affecting meal frequency (Zheng et al., 2005). Furthermore, the classical satiety hormone cholecystokinin (CCK) and the longer-lasting $\alpha \mathrm{MSH}$ synthetic analog melanotan II (MTII) use the cAMP-ERK (extracellular signal-regulated kinase)-cAMP response elementbinding protein cascade in NTS circuits as a common pathway to integrate satiety signals from the gut and adiposity signals from the hypothalamus in the control of meal size and food intake (Sutton et al., 2005). We have also shown that CCK modulates NTScentralis neurons via an increase of glutamatergic synaptic inputs (Baptista et al., 2005a, 2007), an effect that occurs also in POMC neurons of the caudal NTS (Appleyard et al., 2005).

Despite increasing evidence of the involvement of brainstem vagal circuits in the satiety effects of the melanocortin system, the cellular actions of $\alpha \mathrm{MSH}$ on NTS neurons have not been investigated. The aim of the present work was to explore the modulation of glutamatergic synapses impinging on NTS neurons by melanocortinergic agonists.

\section{Materials and Methods}

Research reported in the present study conforms fully to National Institutes of Health guidelines and was approved by the Pennington Biomedical Research Center-Louisiana State University System Institutional Animal Care and Use Committee.

Electrophysiology. The methods of preparing the brainstem slices and the identification of NTS neurons have been described previously (Baptista et al., 2005a,b, 2007). Briefly, 25- to 35-d-old Sprague Dawley rats of either sex were anesthetized with isoflurane (abolition of the foot pinch withdrawal reflex) before being killed by administration of a bilateral pneumothorax. After removal, the brainstem was glued to the platform of a vibratome, and three to four coronal slices (300 $\mu \mathrm{m}$ thick) were cut starting from the caudal area postrema and moving rostrally. The slices were incubated at $30 \pm 1^{\circ} \mathrm{C}$ in Krebs' solution (in mm: $126 \mathrm{NaCl}, 25$ $\mathrm{NaHCO}_{3}, 2.5 \mathrm{KCl}, 1.2 \mathrm{MgCl}_{2}, 2.4 \mathrm{CaCl}_{2}, 1.2 \mathrm{NaH}_{2} \mathrm{PO}_{4}$, and 5 dextrose, maintained at $\mathrm{pH} 7.4$ by bubbling with $95 \% \mathrm{O}_{2}-5 \% \mathrm{CO}_{2}$ ) bubbled with $95 \% \mathrm{O}_{2} / 5 \% \mathrm{CO}_{2}$ for $60-90$ min before use. A single slice was then transferred to a perfusion chamber (volume, $500 \mu \mathrm{l}$; Michigan Precision Instruments, Parma, MI), kept in place with a nylon mesh, and maintained at $35 \pm 1{ }^{\circ} \mathrm{C}$ by perfusion with warmed Krebs' solution at a rate of 2.5-3.0 $\mathrm{ml} / \mathrm{min}$. Recordings were made with patch pipettes (6-8 $\mathrm{M} \Omega$ resistance) filled with a potassium gluconate solution (in mM: $128 \mathrm{~K}$ gluconate, 10 $\mathrm{KCl}, 0.3 \mathrm{CaCl}_{2}, 1 \mathrm{MgCl}_{2}, 10 \mathrm{HEPES}, 1$ EGTA, 2 ATP, $0.25 \mathrm{GTP}$, adjusted to $\mathrm{pH} 7.35$ with $\mathrm{KOH}$ ) by using either an Axopatch 200B or an Axopatch 1D amplifier (Molecular Devices, Sunnyvale, CA). Liquid junction potential was compensated at the beginning of the experiment. Recordings were accepted only if the series resistance was $<20 \mathrm{M} \Omega$. The Krebs' solution contained $50 \mu \mathrm{m}$ picrotoxin to isolate glutamatergic currents pharmacologically, and recordings were conducted at a holding potential (HP) of $-60 \mathrm{mV}$ (i.e., close to $\mathrm{E}_{\mathrm{Cl}}$ ). We have shown previously that the currents recorded under these conditions comprise glutamatergic ionotropic currents only (Baptista et al., 2005a,b).

Whole-cell recordings of spontaneous and miniature glutamatergic EPSCs were conducted on NTS neurons located dorsal to the vagal motoneurons and medial to the tractus solitarius at levels spanning from the posterior tip of the area postrema to $\sim 0.5 \mathrm{~mm}$ rostral to its anterior portion.

In a group of experiments, a bipolar tungsten electrode was placed in the tractus solitarius, and paired pulses of DC current (up to $0.2 \mathrm{~ms}$ long, separated by $20-50 \mathrm{~ms} ; 0.1 \mathrm{~Hz}$ ) were delivered while recording evoked EPSCs from NTS neurons. In another group of animals, the tractus solitarius was stimulated contralateral to the recording site. In these experiments, we used parameters of current intensity and duration one order of magnitude larger that those necessary to evoke maximal EPSC amplitude in ipsilateral NTS neurons. In a final series of experiments, the extracellular $\mathrm{Ca}^{2+}$ concentration was reduced from 2.4 to $1.5 \mathrm{~mm}$. These exper- iments were performed with the intent of decreasing the release probability and thus facilitating the observation of agonist-induced excitatory effects.

Data were sampled at $10 \mathrm{kHz}$ and filtered at $2 \mathrm{kHz}$, digitized via a Digidata 1322 interface (Molecular Devices), acquired with a personal computer using pClamp9 software (Molecular Devices), and analyzed with Mini Analysis software (Jaejin Software, Leonia, NJ).

Drugs were applied to the bath via a series of manually operated valves. Neurons were allowed to recover fully between additions of agonists (minimum washout period of $10 \mathrm{~min}$ ). Cells were classified as responsive if perfusion with $\alpha \mathrm{MSH}$ or MTII (both at $500 \mathrm{~nm}$ ) modified the frequency of spontaneous EPSCs (sEPSCs) by a minimum of 50\% from baseline (measured as the average frequency during $1 \mathrm{~min}$ of recording in control conditions versus $30 \mathrm{~s}$ of recording centered around peak drug response) or the amplitude of evoked EPSCs (eEPSCs) by a minimum of $10 \%$ of control. Holding currents were measured in all the neurons in which there was at least a 5-s-long trace without confounding spontaneous or miniature events. MTII or $\alpha \mathrm{MSH}$ were considered as having postsynaptic effects if there was an agonist-induced current of at least 10 pA that returned to baseline after washout.

Vagal deafferentation. Surgical vagal deafferentation was achieved by sectioning the vagal afferent nerve rootlets (supranodose afferent rhizotomy) in six rats using a technique described previously (Browning et al., 2006; Baptista et al., 2007). Rats were anesthetized with an intramuscular injection of a mixture of ketamine/xylazine/acepromazine $(80,1.6,5$ $\mathrm{mg} / \mathrm{ml} / \mathrm{kg}^{-1}$, respectively) and placed in a stereotaxic frame. After a dorsolateral incision at the level of the occipital bone, muscle tissue was blunt dissected to expose the occipital bone and the first cervical vertebra; after a gentle trimming of the rostral portion of the occipital condyle, the three supranodose vagal dorsal afferent rootlets can be visualized beneath the laterocaudal portion of the occipital plate. Once visualized, the supranodose dorsal rootlets on one of the vagal trunks were sectioned under microscopic guidance using a 27 gauge surgical needle. The complete resection of the rootlets was assessed and confirmed routinely by the person assisting the surgery; three of these rats were used to provide anatomical proof of the successful rhizotomy. In these rats, $4 \mathrm{~d}$ after vagal deafferentation, the nodose ganglia were exposed by blunt dissection of the neck muscles. The sheath surrounding the nodose ganglion was incised to allow insertion of a glass micropipette containing a 5\% solution of rhodamine dextran (lysine fixable; molecular weight, 3000), and pressure pulses were applied to inject $\sim 0.1 \mu \mathrm{l}$ of the dye. The pipette was withdrawn, the area blotted dry, and the cervical incision closed with 4-0 suture. Three to $5 \mathrm{~d}$ later, the rats were anesthetized deeply (isoflurane $5 \%$ ) and perfused transcardially with saline followed by Zamboni's fixative. The brainstem was extracted, postfixed in Zamboni's fixative overnight at $4^{\circ} \mathrm{C}$, washed out, and sliced at $40 \mu \mathrm{m}$ thickness. Every third slice was placed onto gelatin-coated coverslips and mounted with Fluoromount (Southern Biotechnology, Birmingham, AL) to reduce fading. Confocal microscopic images were collected by using a Carl Zeiss (Thornwood, NY) 510 confocal scanning laser microscope equipped with a $\mathrm{Kr} / \mathrm{Ar}$-ion laser and filters for the selective visualization of rhodamine. Two Z-sections separated by $5 \mu \mathrm{m}$ were taken (final magnification, $100 \times)$, and their projections were merged. Overlapping panels of the entire dorsal vagal complex (DVC) area were digitally enhanced and montaged using NIH Image and Adobe Photoshop software (Adobe Systems, Mountain View, CA).

Electrophysiological recordings were made 4-7 d after surgical rhizotomy in the three remaining rats. Three additional rats were anesthetized, the neck muscles were blunt dissected, and a complete vagotomy was conducted by removing a $2-3 \mathrm{~mm}$ portion of the cervical vagus. Again, electrophysiological experiments were conducted $4-7 \mathrm{~d}$ after the surgeries. The data obtained from these groups of rats were pooled, because no qualitative nor quantitative differences were observed in the rats that underwent either deafferentation or complete unilateral vagotomy.

Morphological reconstructions and immunocytochemistry. At the conclusion of electrophysiological recording, the position of the neuron was noted before Neurobiotin was injected by passing positive current pulses into the NTS neuron ( $1 \mathrm{~s}$ duration, $0.5 \mathrm{~Hz}$ for $20 \mathrm{~min}$ ); the brainstem slice was then fixed overnight at $4^{\circ} \mathrm{C}$ in Zamboni's solution [1.6\% (w/v) para- 
formaldehyde, $19 \mathrm{mM} \mathrm{KH}_{2} \mathrm{PO}_{4}$, and $100 \mathrm{~mm} \mathrm{Na} \mathrm{HPO}_{4}$ in $240 \mathrm{ml}$ of saturated picric acid- $1600 \mathrm{ml}$ of $\mathrm{H}_{2} \mathrm{O}$; adjusted to $\mathrm{pH} 7.4$ with $\mathrm{HCl}$. The fixative was cleared from the slice with multiple washes of PBS (in mм: $115 \mathrm{NaCl}, 75 \mathrm{Na}_{2} \mathrm{HPO}_{4} \cdot 7 \mathrm{H}_{2} \mathrm{O}, 7.5 \mathrm{KH}_{2} \mathrm{PO}_{4}, 0.15 \%$ Triton X-100, and $0.1 \%$ bovine serum albumin), and the injected neurobiotin was visualized using a cobalt-nickel enhancement of the Avidin D-horseradish peroxidase $(0.05 \%$ diaminobenzidine in $\mathrm{PBS}$ containing $0.5 \%$ gelatin supplemented with $0.025 \% \mathrm{CoCl}_{2}$ and $0.02 \% \mathrm{NiNH}_{4} \mathrm{SO}_{4}$ ) technique as described previously (Browning et al., 1999, 2005; Martinez-Pena y Valenzuela et al., 2004; Baptista et al., 2005b; Wan et al., 2007).

Neurolucida software (Microbrightfield, Williston, VT) was used to make three-dimensional reconstructions of the individual Neurobiotinlabeled neurons, digitized at a final magnification of $600 \times$. Data analysis was performed as described previously (Browning et al., 1999, 2005; Martinez-Pena y Valenzuela et al., 2004; Baptista et al., 2005b; Wan et al., 2007). Micrograph of representative neurons were taken using a Spot Insight camera and software (Diagnostic Instruments, Sterling Heights, MI) connected to a Nikon (Tokyo, Japan) E400 microscope; the contrast and brightness of the micrographs were digitally enhanced with Adobe software (Adobe Systems).

In another set of neurons, after injection of Neurobiotin and overnight fixation in Zamboni's solution, the slice was cleared of fixative by washing it repeatedly in PBS before overnight incubation at room temperature in PBS containing Triton X-100 and bovine serum albumin (PBS-TXBSA) containing mouse anti-tyrosine hydroxylase $(\mathrm{TH})(1: 10,000)$. Slices were then washed in PBS-TX and incubated for $2 \mathrm{~h}$ at $37^{\circ} \mathrm{C}$ with PBS-TX-BSA containing secondary antibodies (goat anti-mouse conjugated with Alexa 488-FITC 1:500 to visualize TH staining, and streptavidin-Texas Red 1:100 to visualize the Neurobiotin-filled neuron). The slices were then mounted in Fluoromount-G (Southern Biotechnology) to reduce fading and analyzed for immunofluorescence using a Zeiss 510 confocal laser scanning microscope equipped with a $\mathrm{Kr} / \mathrm{Ar}$-ion laser.

Reverse transcription-PCR. Melanocortin receptor primers were designed using Primer3 software (Whitehead Institute for Biomedical Research, Cambridge, MD). We used the following sequences: MC2R, forward, 5' gtcccccgtgtactttttca-3', reverse, 5' -gagcactgtggggatatggt- $3^{\prime}$; MC3R, forward, $5^{\prime}$-tctatgccetccgttaccac- $3^{\prime}$, reverse, $5^{\prime}$-agatgcagtaggggttggtg- $3^{\prime}$; MC4R, forward, $5^{\prime}$-gcgcaattaccttgaccatt- $3^{\prime}$, reverse, $5^{\prime}$-tcaggttgtgcctgagtgac- $3^{\prime}$; MC5R, forward, $5^{\prime}$-cagcctcttggagaacatcc- $3^{\prime}$, reverse, $5^{\prime}$-cgtcatgatgtggtggtagc- $3^{\prime}$. The sequence alignments were validated for specificity using basic local alignment search tool and indicated $100 \%$ identity between the sequence and MC2R, MC3R, MC4R, and MC5R of the rat (GenBank accession numbers NC_005117, NM_0010252703, NM_013099, and NM_013182, respectively).

For validation of receptor expression, RNA was isolated using QIAGEN RNEasy isolation kits (QIAGEN Sciences, Germantown, MD) on tissues from six frozen rat liver, brainstem, hypothalamus, and nodose ganglion. cDNA was derived using iScript cDNA synthesis kit (Bio-Rad, Hercules, CA). Melanocortin receptor PCR was conducted using PCR High Fidelity Supermix (Invitrogen) along with $10 \mathrm{~mm}$ forward and reverse primers and $1 \mu \mathrm{g}$ of template cDNA.

PCR amplification was conducted at the following temperatures and times: $95^{\circ}$ for $2 \mathrm{~min} ; 94^{\circ}$ for $30 \mathrm{~s}, 60^{\circ}$ for $30 \mathrm{~s}, 72^{\circ}$ for $30 \mathrm{~s}$ for 35 cycles; $72^{\circ}$ for $5 \mathrm{~min}$. Ethidium bromide ( $5 \mu \mathrm{g} / \mathrm{mg}$ ) was added to the PCR products, which were then run on a $2 \%$ agarose gel. Primers were designed to yield a $300-400$ base pairs product.

Drugs and chemicals. Tetrodotoxin (TTX) was purchased from Alomone Labs (Jerusalem, Israel). Tyrosine hydroxylase antibodies were purchased from Calbiochem (San Diego, CA); Alexa 488-conjugated goat $\alpha$-mouse IgG was purchased from Invitrogen (Eugene, OR); and streptavidin-Texas Red was purchased from Vector Laboratories (Burlingame, CA). MTII, SHU9119, and $\alpha \mathrm{MSH}$ were purchased from Phoenix Pharmaceuticals (Belmont, CA). All other salts were purchased from Sigma-Aldrich (St. Louis, MO). Stock solutions (1000× concentration) were aliquoted and stored at $-20^{\circ} \mathrm{C}$ and diluted to the final concentration in Krebs' solution just before use.

Statistical analysis. Results are expressed as means \pm SEM with significance defined as $p<0.05$. Results were compared before and after drug administration, with each neuron serving as its own control (Student's paired $t$ test). Intergroup comparisons were conducted using the Student's grouped $t$ test or the $\chi^{2}$ test.

\section{Results}

Electrophysiological recordings were made from 200 NTS neurons obtained from 56 rats; in 28 of these neurons, morphological reconstructions were obtained from both the soma and the dendritic arborization, whereas in an additional 62 neurons, the morphology of the soma shape only was reconstructed. Eighteen neurons were also tested for the presence of tyrosine hydroxylase immunoreactivity.

\section{$\alpha \mathrm{MSH}$ and MTII modulate glutamatergic spontaneous currents in a subpopulation of NTS neurons}

When recorded at an HP of $-60 \mathrm{mV}$, sEPSCs had a frequency of $1.6 \pm 0.24$ events/s, an amplitude of $35 \pm 2.6 \mathrm{pA}$, a $20-80 \%$ rise time of $0.39 \pm 0.08 \mathrm{~ms}$, and a $90-37 \%$ decay time of $2.6 \pm 0.44$ $\mathrm{ms}(n=9)$ (data not shown). Pretreatment with either kynurenic acid ( $1 \mathrm{~mm}$ ) or a solution containing CNQX and APV (10 and 30 $\mu \mathrm{M}$, respectively) abolished the events, indicating that the sEPSC were glutamatergic (Baptista et al., 2005a).

In 11 of 31 NTS neurons (i.e., 35\%), perfusion with $\alpha \mathrm{MSH}$ $(500 \mathrm{nM})$ increased the frequency of sEPSCs from $1.1 \pm 0.23$ to $2.7 \pm 0.59$ events/s (i.e., $233 \pm 21.6 \%$ of control). Event frequency returned to baseline (i.e., $1.1 \pm 0.28$ events/s) after washout. In these same neurons, perfusion with $\alpha \mathrm{MSH}$ did not affect the amplitude of the events (i.e., $36 \pm 6.9$ and $42 \pm 3 \mathrm{pA}$ in control and in $\alpha \mathrm{MSH}$, respectively) ( $p>0.05)$. In 2 of 31 neurons (i.e., 6.5\%), perfusion with $\alpha \mathrm{MSH}$ (500 nM) decreased the frequency of sEPSCs from 1.8 to 0.87 and from 2.1 to 0.1 events/s, respectively. After washout of $\alpha \mathrm{MSH}$, event frequency recovered to 1.7 and 0.6 events/s, respectively. In the same two neurons, perfusion with $\alpha \mathrm{MSH}$ did not affect the amplitude of the events (i.e., $37.5 \pm 4.6$ and $36 \pm 9 \mathrm{pA}$ in control and in $\alpha \mathrm{MSH}$, respectively). The remaining 18 neurons were unresponsive to perfusion with $\alpha \mathrm{MSH}$.

In 18 of 95 NTS neurons (i.e., 19.5\%), perfusion with MTII $(500 \mathrm{nM})$ increased the frequency of sEPSC from $1.8 \pm 0.4$ to $4.9 \pm 1.1$ events/s (i.e., $352 \pm 61 \%$ of control). Event frequency returned to baseline (i.e., $1.6 \pm 0.2$ events/s) after washout. In the same neurons, perfusion with MTII did not affect the amplitude of the events (i.e., $35 \pm 3.4 \mathrm{pA}$ in control and $38 \pm 1.4 \mathrm{pA}$ in control and in MTII, respectively) $(p>0.05)$ (Fig. 1). In five neurons (i.e., 6\%), perfusion with MTII (500 nM) decreased the frequency of sEPSC from $2.2 \pm 0.51$ to $0.75 \pm 0.25$ events/s. The event frequency recovered to $1.56 \pm 0.14$ events/s after washout. In the same neurons, perfusion with MTII did not affect the amplitude of the events (i.e., $30 \pm 7.2$ to $32 \pm 11.9$ pA in control and in MTII, respectively) (data not shown). The remaining neurons were unresponsive to perfusion with MTII. Because the response to $\alpha \mathrm{MSH}$ and MTII were qualitatively and quantitatively similar ( $p>0.05$ for each parameter), we pooled together the data on event frequency while still indicating the number of repetitions for each peptide. The low occurrence of inhibitory responses to either peptide prevented us from additional analysis.

The holding current was monitored in 43 neurons, 13 of which responded to MTII or $\alpha \mathrm{MSH}$ with an increase and five with a decrease in sEPSC frequency. The remaining 25 neurons were unresponsive. In three of the four neurons that showed a postsynaptic effect, perfusion with melanocortinergic agonists induced a $18 \pm 2 \mathrm{pA}$ inward current, whereas in one neuron, there was a $16 \mathrm{pA}$ outward current. The remaining 30 neurons did not show any evidence of a postsynaptic current. 
A

Control
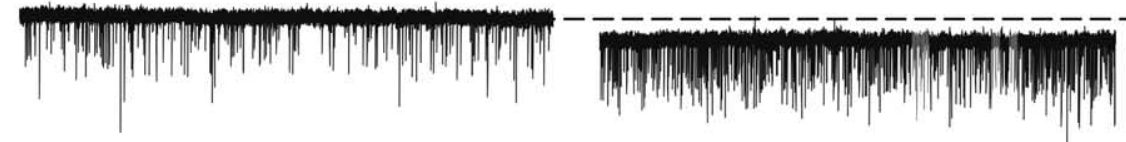

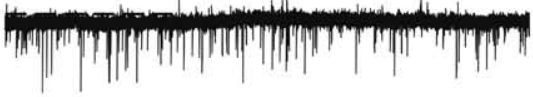
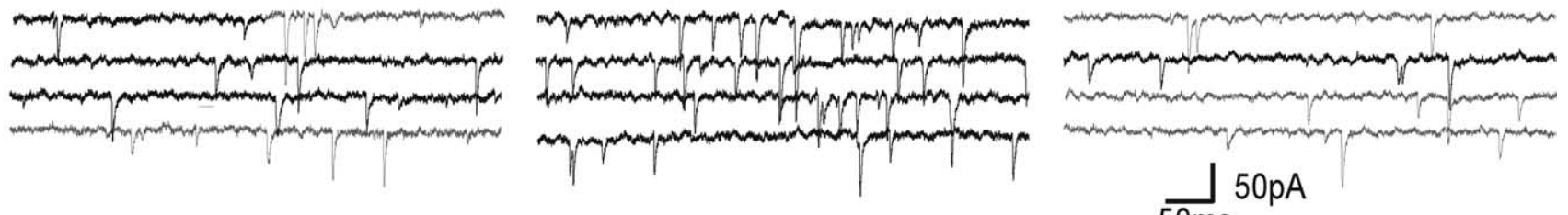

B
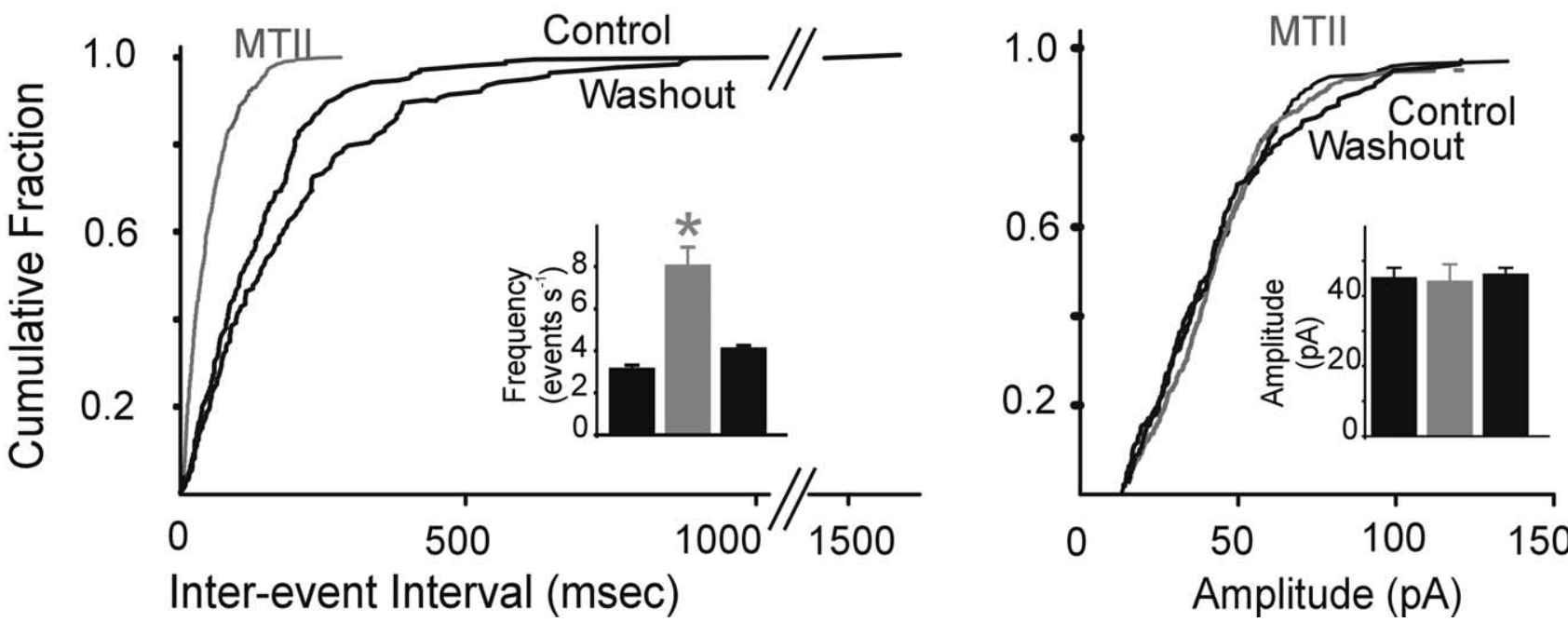

Figure 1. Perfusion with MTII increases the frequency but not the amplitude of glutamatergic SEPSCs. $A$, Representative current traces showing that perfusion with $500 \mathrm{~nm}$ MTII (middle) increased the frequency of sEPSC; the increase was reversible after washout. The four bottom traces represent portions of the top traces but on an expanded time scale. Holding potential, $-60 \mathrm{mV}$. $\boldsymbol{B}$, Frequency histograms for the cell in $\boldsymbol{A}$. Note that perfusion with MTII increases the frequency of sEPSC. Inset, Bar graphs showing the averaged results of frequency for the sEPSC in control, 500 nM MTII, and washout. ${ }^{*} p<0.05$. C, Amplitude histograms for the cell in $A$. Note that perfusion with MTII does not increase the amplitude of sEPSC. Inset, Bar graphs showing the averaged results of amplitude for the SEPSC in control, $500 \mathrm{~nm} \mathrm{MTIl,} \mathrm{and} \mathrm{washout.}$

The response to application with $\alpha \mathrm{MSH}(n=3)$ or MTII ( $n=$ 7) did not show tachyphylaxis, because two perfusions in the same neuron 15 min apart gave similar results. In fact, the first perfusion increased the sEPSC frequency from $2.56 \pm 0.61$ at baseline to a peak of $6.6 \pm 1.62$ events/s (i.e., $297 \pm 40.8 \%$ of control), whereas the second perfusion increased the frequency of sEPSC from a baseline of $2.3 \pm 0.87$ to a peak of $4.5 \pm 1.27$ events/s (i.e., $233 \pm 29.7 \%$ of control; $p>0.05$ vs first perfusion) (data not shown).

Perfusion with $\alpha \mathrm{MSH}$ or MTII modulated the sEPSC frequency but not amplitude, suggesting a possible presynaptic effect of the peptides. To confirm a presynaptic effect, we conducted the experiments in conditions of synaptic blockade (i.e., we measured mEPSCs in the presence of $1 \mu \mathrm{M}$ TTX), because if peptide perfusion still modulates $\mathrm{mEPSC}$ frequency but not amplitude, we can reasonably conclude that the effects of MTII are presynaptic.

In four NTS neurons, perfusion with MTII increased the sEPSC frequency from $1.1 \pm 0.23$ to $3.6 \pm 0.45$ events/s $(p<$ 0.05 ) but did not alter sEPSC amplitude (from $30 \pm 3.7$ to $36 \pm$ $4.7 \mathrm{pA}$ in control and MTII, respectively; $p>0.05)$. After wash- out of the peptide and 15 min perfusion with $1 \mu \mathrm{M}$ TTX, the frequency of mEPSCs was $0.35 \pm 0.01$ events/s, and their amplitude was $26 \pm 6.1 \mathrm{pA}$; reapplication of MTII in the continued presence of TTX increased mEPSC frequency to $3.6 \pm 1.32$ events/s $(p<0.05)$ but did not affect mEPSC amplitude $(36 \pm$ $9.7 \mathrm{pA} ; p>0.05$ ) (Fig. 2).

Furthermore, the $20-80 \%$ rise time and $90-37 \%$ decay time of the EPSC was not affected by perfusion with either MTII or $\alpha \mathrm{MSH}(0.37 \pm 0.06$ and $2.5 \pm 0.32 \mathrm{~ms} ; n=9 ; p>0.05$ vs control) (data not shown). These data indicate that, in our experimental conditions, the effects of the peptides are determined by an action at presynaptic receptors located on terminals impinging on NTS neurons.

In 10 NTS neurons, perfusion with $\alpha$ MSH or MTII ( $n=5$ for both) increased the sEPSC frequency from $1.2 \pm 0.38$ to $2.8 \pm$ 0.78 events/s (i.e., $223 \pm 20.8 \%$ of control; $p<0.05$ ); after washout and 15 min perfusion with a Krebs' solution containing the nonselective MCR3/4 antagonist SHU9119 (1 $\mu \mathrm{M})$, sEPSC frequency was $0.86 \pm 0.21$ events/s $(p>0.05$ vs control). In the continued presence of SHU9119, reapplication of $\alpha \mathrm{MSH}$ or MTII did not alter sEPSC frequency $(0.83 \pm 0.24$ events $/ s)(p>$ 

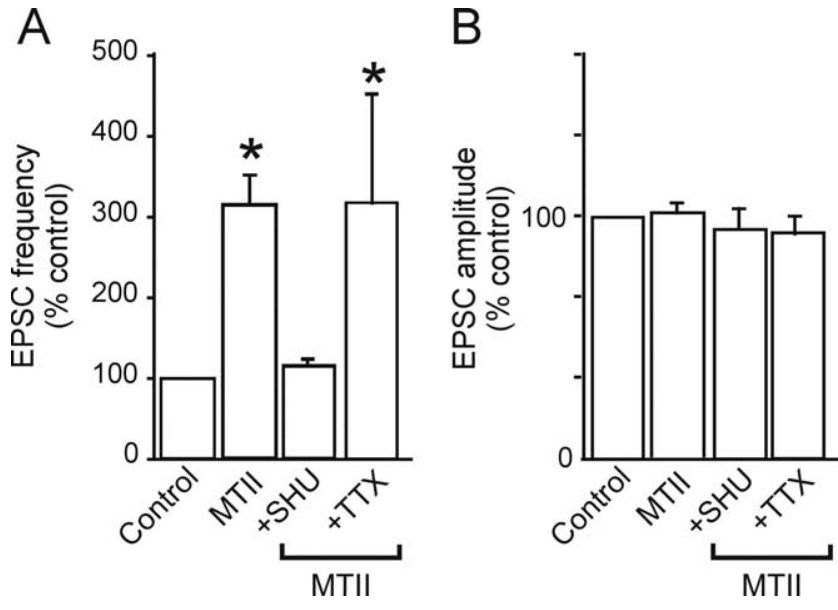

Figure 2. The presynaptic effects of MTII effects are prevented by pretreatment with SHU9119 but not TTX. A, Summary graphic showing that the effects of MTII (500 nM) on sEPSC frequency are prevented by pretreatment with the nonselective MCR3/4 receptor antagonist SHU9119 $(1 \mu \mathrm{M})$. The effects of MTII are also present on mEPSC (i.e., in the presence of $1 \mu \mathrm{M}$ TTX). ${ }^{*} p<0.05$. B, Summary graphic showing the lack of MTIl effects on the amplitude of both SEPSC and $\mathrm{mEPSC}$.

0.05 vs SHU alone) (Fig. 2). These data indicate that the excitatory response to the peptides was mediated by interaction with presynaptic MC3/4R.

Because the major source of glutamatergic input to neurons of the NTS originates from vagal afferent fibers (Champagnat et al., 1986; Mifflin and Felder, 1990; Andresen and Kunze, 1994; Smith et al., 1998; Hornby, 2001; Jean, 2001; Baptista et al., 2005b; Travagli et al., 2006), we hypothesized that the modulation of sEPSCs by $\alpha \mathrm{MSH}$ and MTII may target vagal afferent (sensory) terminals preferentially. We thus conducted a series of experiments in animals in which the vagal afferent terminals were surgically removed.

The effects of MTII on sEPSCs were tested in 34 neurons from six rats that underwent vagal deafferentation or vagotomy $4-7 \mathrm{~d}$ previously. There were no qualitative or quantitative differences in the neurons from these two sets of rats, and the data were thus pooled. In four neurons, perfusion with MTII (500 nM) increased the frequency of sEPSCs from $1.4 \pm 0.46$ to $3.8 \pm 1.15$ events/s $(p<0.05)$; in the remaining 30 neurons, however, MTII did not induce any modulation of sEPSC frequency (Fig. 3).

To further prove the efficacy of the vagal deafferentation procedures, we injected the tracer rhodamine dextran bilaterally in the nodose ganglia of a group of three rats that underwent unilateral deafferentation. Rhodamine-dextran-labeled fibers were absent in the NTS ipsilateral to the lesioned site, but fibers were present in the contralateral NTS (i.e., the intact side) (Fig. 3). Furthermore, electrical stimulation of the tractus solitarius contralateral to the recording site using current duration and intensities up to one order of magnitude larger than those necessary to evoke maximal EPSC amplitude did not evoke EPSCs in contralateral NTS $(n=6)$ (data not shown). These data confirm the complete deafferentation procedures and indicate that the main site of action of MTII is at the level of vagal afferent terminals impinging on NTS neurons, although other neuronal circuits must be considered.

\section{$\alpha \mathrm{MSH}$ and MTII modulate evoked glutamatergic currents in a subpopulation of NTS neurons}

In another series of experiments while recording from NTS neurons, we tested the ability of $\alpha \mathrm{MSH}$ and MTII to modulate the
EPSC (eEPSC) evoked by stimulation of the tractus solitarius. In the four neurons in which we tested both peptides, the results were qualitatively and quantitatively similar; we thus pooled together the data while still indicating the number of repetitions for each peptide.

In 6 of 28 neurons (i.e., 21\%), perfusion with either $\alpha \mathrm{MSH}$ $(n=2)$ or MTII $(n=4$; both at $500 \mathrm{nM})$ increased the amplitude of the eEPSC from $404 \pm 80.2$ to $514 \pm 110.6 \mathrm{pA}$ (i.e., $125 \pm 2.3 \%$ of control; $p<0.05$ ), the eEPSC amplitude recovered to baseline after washout. The paired-pulse ratio, with variation that is indicative of a possible presynaptic site of action (Travagli and Williams, 1996; Meir et al., 1999; Browning et al., 2004), decreased from $0.61 \pm 0.05$ to $0.49 \pm 0.08$ in control and in MTII, respectively $(n=4 ; p<0.05)$ The increase in eEPSC amplitude was concentration dependent (5-500 nM), and it was antagonized by pretreatment with the MC3/4R nonselective antagonist SHU9119 ( $1 \mu \mathrm{M} ; n=4)$ (Fig. 4).

In 14 of 28 neurons (i.e., 50\%), however, perfusion with either $\alpha$ MSH $(n=4)$ or MTII $(n=10$; both at $500 \mathrm{nM})$ decreased the amplitude of the eEPSC from $501 \pm 51.8$ to $380 \pm 43.2 \mathrm{pA}$ (i.e., $74 \pm 3.4 \%$ of control; $p<0.05$ ), the eEPSC amplitude recovered to baseline after washout. Even in this instance, the paired-pulse ratio varied from $0.72 \pm 0.07$ to $0.90 \pm 0.08$ in control and MTII, respectively $(n=14 ; p<0.05)$ The decrease in eEPSC amplitude was concentration dependent, and it was antagonized by pretreatment with SHU9119 ( $n=7)$ (Fig. 4).

In a group of neurons in which perfusion with $500 \mathrm{~nm}$ MTII did not have any effect on the amplitude of the eEPSC (i.e., $415 \pm$ 79 and $418 \pm 70 \mathrm{pA}$ in control and after MTII, respectively; $n=$ 6 ; $p>0.05$ ), we lowered the extracellular $\mathrm{Ca}^{2+}$ concentration from 2.4 to $1.5 \mathrm{~mm}$. In these conditions, the baseline amplitude of the eEPSC was reduced to $269 \pm 40 \mathrm{pA}$, and perfusion with 500 $\mathrm{nM}$ MTII increased it to $350 \pm 43 \mathrm{pA}$ in four of the six neurons $(p<0.05)$. These data suggest that the responses to melanocortinergic agonists are qualitatively similar when considering spontaneous, miniature, or evoked EPSCs but raises the possibility that the percentage of neurons in which melanocortinergic agonists augment eEPSC amplitude may be underestimated during basal recording conditions.

\section{MTII-responsive NTS neurons vary widely in somatic and dendritic morphology}

Of the 73 NTS neurons in which we were able to reconstruct the soma shape, $15(21 \%)$ responded to either MTII or $\alpha \mathrm{MSH}$ with an increase $(n=12)$ or a decrease $(n=3)$ of sEPSC frequency; seven of those 15 neurons had a bipolar soma shape, whereas the remaining eight neurons had a multipolar soma shape. Conversely, of the 57 NTS neurons unresponsive to MTII or $\alpha \mathrm{MSH}$, 25 had a bipolar soma shape, whereas the other 32 neurons had a multipolar soma shape ( $p>0.05$ vs responsive neurons; $\chi^{2}$ test) (Fig. 5).

Regardless of the response to MTII or $\alpha \mathrm{MSH}$ (or lack thereof) and the relative location within the rostrocaudal extent of the NTS, none of the neurons tested were positive for tyrosine hydroxylase immunoreactivity $(n=18)$ (Fig. 6). Together, these data indicate that NTS neurons responsive to melanocortin agonists do not have distinguishing morphological features.

Vagal afferent neurons in the nodose ganglia express MC4 but not MC3 receptors

mRNA for MC4R, but not MC3R, was detected in both the nodose ganglia and the portion of the dorsal brainstem comprising 
the NTS; conversely, mRNA for both MC3R and MC4R was detected in the hypothalamus but not in the liver (Fig. 7).

\section{Discussion}

Behavioral and anatomical studies in rodents suggest that melanocortinergic signaling at the level of the caudal brainstem plays an important role in homeostatic regulatory pathways, including those controlling satiation. We used electrophysiological and biochemical methods to elucidate the potential cellular mechanisms. We show the following: (1) melanocortinergic signaling leads to a mainly presynaptic modulation of glutamatergic synaptic transmission; (2) MC4R expressed on the vagal nerve terminals can facilitate or inhibit glutamatergic currents in NTS; (3) activation of MC4R on nonvagal nerve terminals facilitates glutamatergic currents in NTS; and

(4) MC4Rs but not MC3Rs are expressed in the nodose ganglia and caudal brainstem.

We suggest that $\alpha \mathrm{MSH}$ may modulate homeostatic functions, including satiation, by the presynaptic modulation of vagal glutamatergic inputs to NTS neurons. Our conclusions are supported by the following experimental evidence.

\section{MC4R modulation of glutamatergic synaptic transmission is mainly presynaptic}

$\alpha \mathrm{MSH}$, or its stable analog MTII, increases the frequency of spontaneous and miniature glutamatergic EPSCs in NTS neurons, leaving their amplitude, rise, and decay kinetics unchanged, suggestive of a presynaptic site of action (Katz, 1962). Additional support for a presynaptic site of action is given by the variation in the paired-pulse ratio of the amplitude of evoked currents (Travagli and Williams, 1996; Meir et al., 1999; Browning et al., 2004).

The responses to melanocortinergic agonists (MTII or $\alpha \mathrm{MSH}$ ) indicate the involvement of either MC3R or MC4R (Alexander et al., 2007). Immunocytochemical, in situ hybridization, and binding studies have identified both MC3R and MC4R in the DVC, and their role in food satiation has been suggested by behavioral studies (Joseph et al., 1985; Palkovits et al., 1987; Bronstein et al., 1992; Grill et al., 1998; Williams et al., 2000; Kishi et al., 2003; Liu et al., 2003; Fan et al., 2004; Zheng et al., 2005). Although our pharmacological experiments could not differentiate between MC3R and MC4R, our reverse transcription-PCR results reveal that mRNA for only MC4R is present in the nodose ganglia and in the dorsal caudal brainstem area, suggesting the effects of melanocortin agonists occur via MC4R only.

\section{MC4R expressed on central terminals of vagal afferent fibers} can attenuate or enhance glutamatergic currents in NTS

A smaller proportion of neurons responded to melanocortin agonists with an increase in eEPSC amplitude than with an excitation of sEPSC frequency. Experimentally, it is easier to observe an increase in sEPSC (or mEPSC) frequency because of the relatively low rate of frequency. In contrast, recording eEPSC in high calcium makes facilitatory responses difficult to observe because of the high probability of glutamate release onto NTS neurons under basal $\mathrm{Ca}^{2+}{ }_{\mathrm{e}}$. Recently, Bailey et al. (2006b) demonstrated that the probability of release from vagal terminals onto cardiovascu- lar NTSmedialis neurons is $\sim 0.9$ when bathed in $2 \mathrm{mM} \mathrm{Ca}^{2+}$ Because fibers impinging onto NTScentralis neurons may have similar release characteristics, the effects of MTII were tested when the probability of release was reduced. In these conditions, indeed, a larger percentage of neurons responded with an increased eEPSC after MC4R activation. A conservative interpretation of our results suggests that the percentage of NTS neurons in which melanocortinergic agonists augment eEPSC amplitude may be underestimated during basal recording conditions.

The different ratio of eEPSC excitation/inhibition compared with sEPSC may also be caused by activation of multiple synaptic inputs by electrical stimulation. Although submaximal electrical stimulation of the tractus solitarius was used, the anatomical organization of the coronally sectioned caudal brainstem makes it likely that multiple fibers were recruited, unlike the horizontal brainstem preparation that restricts the stimulation to solitary fibers (Doyle and Andresen, 2001; Bailey et al., 2002, 2006a; Jin et al., 2004). Nonvagal fibers of passage may also be stimulated during our paradigm, because several CNS areas that project to the NTS use glutamate as a neurotransmitter (Blessing, 1997; Schaffar et al., 1997; Lin et al., 2000)

MC4R expressed on nonvagal inputs to NTS neurons enhance glutamatergic currents exclusively

The MC4R activated in our experimental conditions appear to be located principally, but not exclusively, on vagal afferent fibers. In fact, in "vagally intact" preparations, a larger percentage of NTS neurons responds to MC4R activation than in rats that underwent previous surgical vagal deafferentation. These data indicate that the main site of melanocortinergic modulation is at the level of the vagal afferent terminals impinging on NTS neurons, although the involvement of other glutamatergic circuits of nonvagal origin should be considered. In contrast to vagally intact rats, where a limited number of NTS neurons responded to MC4R activation with a decrease in sEPSC, the response to MC4R activation was exclusively excitatory in deafferented rats. These data indicate that although melanocortins exert homogeneous actions on nonvagal inputs, they exert heterogeneous actions on vagal glutamatergic synapses. One possible explanation for this may be that some recordings may have been made from NTS neurons that were not second order (i.e., from local interneurons).

The question then arises as to the source of the $\alpha \mathrm{MSH}$ - 

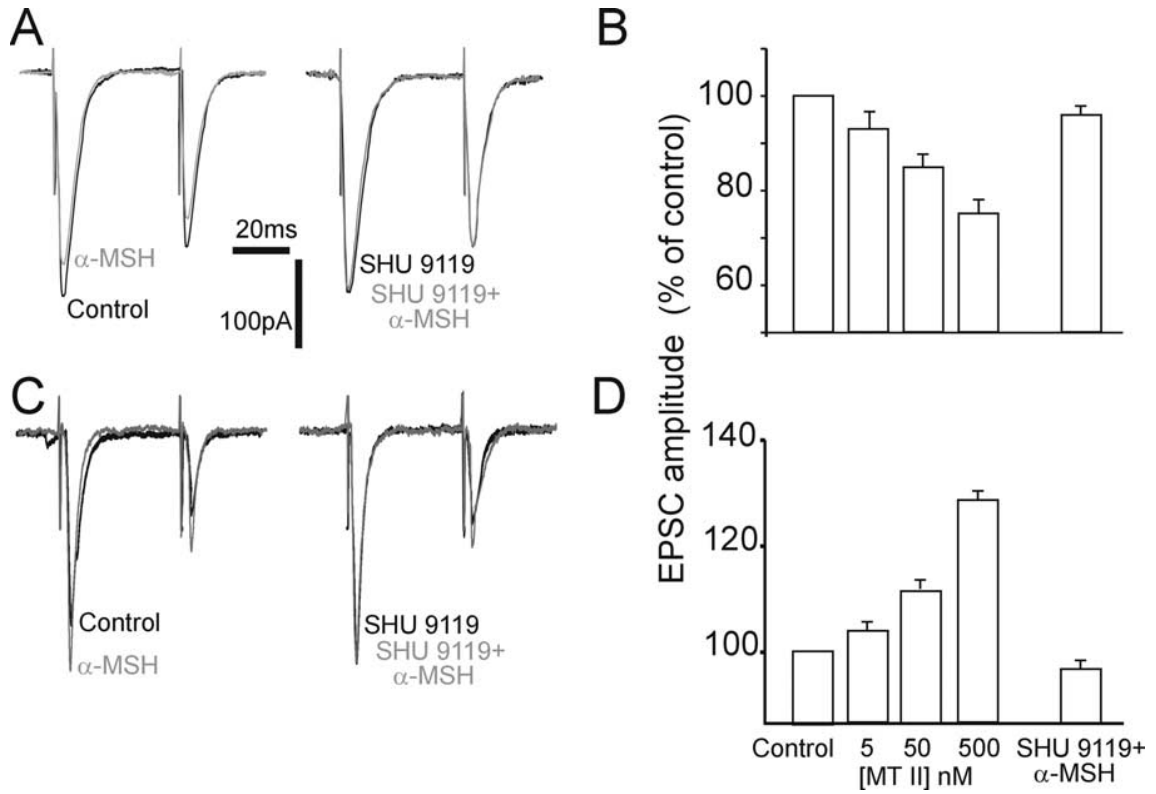

Figure 4. Effects of perfusion with $\alpha \mathrm{MSH}$ on the amplitude of eEPSC. $\boldsymbol{A}$, Original representative traces showing that in an NTS neuron voltage clamped at $-60 \mathrm{mV}$, the amplitude of the eEPSCs evoked by electrical stimulation of the adjacent tractus solitarius was reduced by perfusion with $500 \mathrm{~nm} \alpha \mathrm{MSH}$ (left); pretreatment with $1 \mu \mathrm{m}$ SHU9119 prevented the inhibitory effects of $\alpha \mathrm{MSH}$ (right). Similar results were obtained with MTII. $\boldsymbol{B}$, Summary graphic showing that the inhibition of eEPSC amplitude by MTII was concentration dependent (5-500 nM), and it was prevented by pretreatment with SHU9119. C, Original representative traces showing that, in a different NTS neuron voltage clamped at $-60 \mathrm{mV}$, the amplitude of the eEPSCs evoked by electrical stimulation of the adjacent tractus solitarius was increased by perfusion with $500 \mathrm{~nm} \alpha \mathrm{MSH}$ (left); pretreatment with $1 \mu \mathrm{M}$ SHU9119 prevented the facilitatory effects of $\alpha \mathrm{MSH}$ (right). Similar results were obtained with MTII. D, Summary graphic showing that the increase of eEPSC amplitude by MTII was concentration dependent (5-500 nm), and it was prevented by pretreatment with SHU9119. The $x$-axis applies to both $\boldsymbol{B}$ and $\boldsymbol{D}$
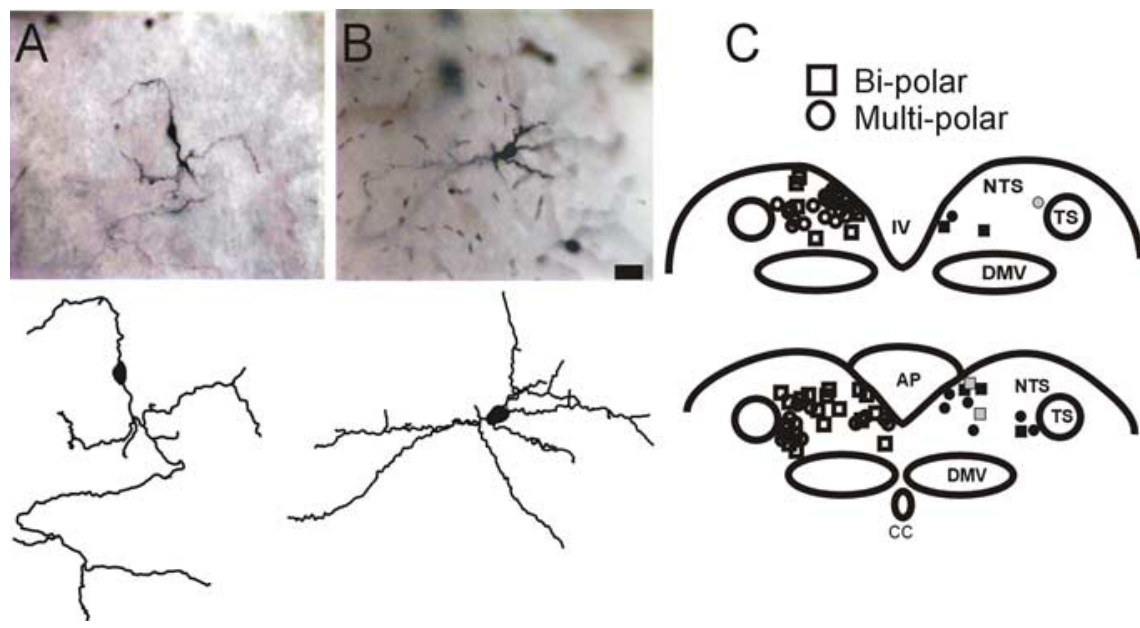

Figure 5. Morphology and localization of NTS neurons responsive to MTII and/or $\alpha M S H$. $\boldsymbol{A}$, Micrograph (top) and computeraided reconstruction (bottom) of a representative NTS neuron with bipolar soma shape. $\boldsymbol{B}$, Micrograph (top) and computeraided reconstruction (bottom) of a representative NTS neuron with multipolar soma shape. $\boldsymbol{C}$, Schematic diagram depicting the localization of NTS neurons according to their soma shape (square, bipolar; circle, multipolar) and their response to perfusion with either MTII or $\alpha$ MSH (gray symbol, inhibited; black symbol, excited; white symbol, nonresponsive). For the purpose of intelligibility, all the responsive neurons are depicted on the right side of the scheme, whereas the nonresponsive neurons are depicted on the left side of the scheme. TS, Tractus solitarius; DMV, dorsal motor nucleus of the vagus; AP, area postrema; IV, fourth ventricle.

containing fibers making synaptic contacts with glutamatergic fibers in the NTS. In the CNS, POMC neurons are restricted to the arcuate nucleus and NTScommissuralis (Gee et al., 1983; Palkovits et al., 1987; Bronstein et al., 1992; Appleyard et al., 2005). We recently provided anatomical evidence that hypotha- lamic POMC axons project to the DVC (Zheng et al., 2005), and knife cut experiments suggested that most of the $\alpha \mathrm{MSH}$ containing fibers in the rostral NTS are of hypothalamic origin (Palkovits et al., 1987). The vast arborization of NTS neurons, however, means that release of $\alpha \mathrm{MSH}$ from local POMC neurons may also contribute to the melanocortinergic modulation of the glutamate synapses on NTS. Indeed, POMC neurons in the caudal NTS are activated by intraperitoneal administration of the satiety hormone CCK, suggesting that these neurons may play a key role in the gastrointestinal-mediated inhibitory feedback on food intake (Appleyard et al., 2005).

\section{Implications for the control of food intake}

Activation of brainstem melanocortin receptors inhibits food intake potently with a concomitant increase in energy expenditure (Grill et al., 1998; Williams et al., 2000; Fan et al., 2004; Zheng et al., 2005). Here, we provided a possible cellular mechanism (i.e., a melanocortin-mediated increase in glutamate transmission to NTS neurons).

Vagal afferent fibers use glutamate as their main transmitter onto NTS neurons (Andresen and Yang, 1990; Smith et al., 1998; Jean, 2001; Baptista et al., 2005b; Travagli et al., 2006) and intraperitoneal administration of satiety agents (e.g., CCK, glucagon-like peptide-1, or cocaine- and amphetamine-regulated transcript) increases c-Fos expression in NTS (Rinaman et al., 1993; Zittel et al., 1999; Sayegh and Ritter, 2000; Zheng et al., 2002b; Cano et al., 2003; Gulley et al., 2005; Arora and Anubhuti, 2006; Berthoud et al., 2006), including the POMC neurons of the caudal NTS (Appleyard et al., 2005). This c-Fos expression is likely caused by increased glutamate release, because administration of glutamatergic antagonists decreases satiety (Covasa et al., 2004a,b; Zheng et al., 1999, 2002a). Furthermore, perfusion with anorexigenic hormones, such as CCK, increase vagal glutamatergic inputs to NTS (Simasko and Ritter, 2003; Baptista et al., 2005a). Our data are consistent with the idea that brainstem melanocortins suppress food intake by enhancing vagal satiation signals.

Melanocortins were also observed to decrease glutamatergic transmission to a subpopulation of NTS neurons. Because increased glutamatergic inputs to NTS neurons signals is generally assumed to signal satiety, it is not clear how this melanocortin-induced inhibition could result in satiation. The NTS receives a vast array of visceral sensory inputs, however, including cardiac and baroreceptor afferents. Hence, some of the neurons recorded may have been part of cardiac or 
baroreceptor circuits (Andresen and Kunze, 1994). Melanocortins influence cardiovascular circuits (Versteeg et al., 1998), and the correlation between obesity and high blood pressure suggest that melanocortinergic neurotransmission within NTS provides a link between energy and cardiovascular homeostatic circuits (Appleyard et al., 2005).

An alternative explanation for these apparently contradictory melanocortin effects correlates meal satiation to decreased gastrointestinal motility. Preganglionic neurons of the DMV use two distinct postganglionic vagal effector pathways to control gastrointestinal motility: a tonic excitatory cholinergic pathway and an inhibitory nonadrenergic noncholinergic (NANC) pathway. DMV neurons receive robust GABAergic inputs from NTS neurons (Travagli et al., 2006), and gastric distention can result from reduced activation of these GABAergic inputs onto DMV neurons within the NANC pathway. Disinhibition of these preganglionic neurons (through melanocortin-induced inhibition of NTS neurons) may increase NANC activity, resulting in gastric relaxation, decreased motility, and satiety.

The NTS comprises a vast array of neurons with different neurochemical and morphological properties (Zhang et al., 1995; Blessing, 1997; Deuchars et al., 2000; Paton et al., 2000; Travagli et al., 2006). Recently, Bailey et al. (2006a) correlated morphological and electrophysiological properties of NTS neurons with their projections to either the hypothalamus or the CVLM area. In the present work, we did not observe any distinctive identifier for melanocortin-responsive or -unresponsive NTS neurons, perhaps indicating the involvement of melanocortins in more than one function controlled by NTS brainstem circuits.

In summary, activation of MC4R modulates glutamatergic inputs to subpopulation of NTS neurons, via mainly excitatory actions on presynaptic MC4R on vagal and nonvagal fibers. We propose that one of the mechanisms used by $\alpha \mathrm{MSH}$ to suppress food intake is via presynaptic modulation of the glutamatergic synapse impinging on those NTS neurons involved in mechanisms of satiation.

\section{References}

Alexander SP, Mathie A, Peters JA (2007) 7TM receptors. Br J Pharmacol 150:S4-S81.

Andresen MC, Kunze DL (1994) Nucleus tractus solitarius-gateway to neural circulatory control. Annu Rev Physiol 56:93-116.

Andresen MC, Yang M (1990) Non-NMDA receptors mediate sensory afferent synaptic transmission in medial nucleus tractus solitarius. Am J Physiol 259:H1307-H1311.

Appleyard SM, Bailey TW, Doyle MW, Jin YH, Smart JL, Low MJ, Andresen MC (2005) Proopiomelanocortin neurons in nucleus tractus solitarius are activated by visceral afferents: regulation by cholecystokinin and opioids. J Neurosci 25:3578-3585.

Arora S, Anubhuti (2006) Role of neuropeptides in appetite regulation and obesity-a review. Neuropeptides 40:375-401.
Bailey TW, Jin YH, Doyle MW, Andresen MC (2002) Vanilloid-sensitive afferents activate neurons with prominent A-type potassium currents in nucleus tractus solitarius. J Neurosci 22:8230-8237.

Bailey TW, Hermes SM, Andresen MC, Aicher SA (2006a) Cranial visceral afferent pathways through the nucleus of the solitary tract to caudal ventrolateral medulla or paraventricular hypothalamus: target-specific synaptic reliability and convergence patterns. J Neurosci 26:11893-11902.

Bailey TW, Jin YH, Doyle MW, Smith SM, Andresen MC (2006b) Vasopressin inhibits glutamate release via two distinct modes in the brainstem. J Neurosci 26:6131-6142.

Baptista V, Zheng Z, Coleman FH, Rogers RC, Travagli RA (2005a) Cholecystokinin octapeptide increases spontaneous glutamatergic synaptic transmission to neurons of the nucleus tractus solitarius centralis. J Neurophysiol 94:2763-2771.

Baptista V, Zheng ZL, Coleman FH, Rogers RC, Travagli RA (2005b) Characterization of neurons of the nucleus tractus solitarius pars centralis. Brain Res 1052:139-146.

Baptista V, Browning KN, Travagli RA (2007) Effects of cholecystokinin-8s in the nucleus tractus solitarius of vagally deafferented rats. Am J Physiol Regul Integr Comp Physiol 292:R1092-R1100.

Berthoud HR (2004) The caudal brainstem and the control of food intake and energy balance. In: Handbook of behavioral neurobiology, Vol 14, Neurobiology of food and fluid intake (Stricker E, Woods S, eds), pp 195-240. New York: Kluwer Academic/Plenum.

Berthoud HR, Earle T, Zheng H, Patterson LM, Phifer C (2001) Foodrelated gastrointestinal signals activate caudal brainstem neurons expressing both NMDA and AMPA receptors. Brain Res 915:143-154.

Berthoud HR, Sutton GM, Townsend RL, Patterson LM, Zheng H (2006) 
Brainstem mechanisms integrating gut-derived satiety signals and descending forebrain information in the control of meal size. Physiol Behav 89:517-524.

Blessing WW (1997) The lower brainstem and bodily homeostasis. Oxford UP.

Bronstein DM, Schafer MK, Watson SJ, Akil H (1992) Evidence that betaendorphin is synthesized in cells in the nucleus tractus solitarius: detection of POMC mRNA. Brain Res 587:269-275.

Browning KN, Renehan WE, Travagli RA (1999) Electrophysiological and morphological heterogeneity of rat dorsal vagal neurones which project to specific areas of the gastrointestinal tract. J Physiol (Lond) 517:521-532.

Browning KN, Kalyuzhny AE, Travagli RA (2004) $\mu$-Opioid receptor trafficking on inhibitory synapses in the rat brainstem. J Neurosci 24:9344-9352.

Browning KN, Coleman FH, Travagli RA (2005) Characterization of pancreas-projecting rat dorsal motor nucleus of the vagus neurons. Am J Physiol Gastrointest Liver Physiol 288:G950-G955.

Browning KN, Zheng Z, Gettys TW, Travagli RA (2006) Vagal afferent control of opioidergic effects in rat brainstem circuits. J Physiol (Lond) 575:761-776.

Cano V, Caicoya E, Ruiz-Gayo M (2003) Effect of peripheral cholecystokinin receptor agonists on c-Fos expression in brain sites mediating food consumption in rats. Neurosci Lett 343:13-16.

Champagnat J, Denavit-Saubie M, Grant K, Shen KF (1986) Organization of synaptic transmission in the mammalian solitary complex, studied in vitro. J Physiol (Lond) 381:551-573.

Cone RD (2005) Anatomy and regulation of the central melanocortin system 1. Nat Neurosci 8:571-578.

Covasa M, Hung CY, Ritter RC, Burns GA (2004a) Intracerebroventricular administration of MK-801 increases food intake through mechanisms independent of gastric emptying. Am J Physiol Regul Integr Comp Physiol 287:R1462-R1467.

Covasa M, Ritter RC, Burns GA (2004b) NMDA receptor blockade attenuates CCK-induced reduction of real feeding but not sham feeding. Am J Physiol Regul Integr Comp Physiol 286:R826-R831.

Deuchars J, Li YW, Kasparov S, Paton JFR (2000) Morphological and electrophysiological properties of neurones in the dorsal vagal complex of the rat activated by arterial baroreceptors. J Comp Neurol 417:233-249.

Doyle MW, Andresen MC (2001) Reliability of monosynaptic sensory transmission in brain stem neurons in vitro. J Neurophysiol 85:2213-2223.

Emond M, Schwartz GJ, Moran TH (2001) Meal-related stimuli differentially induce c-Fos activation in the nucleus of the solitary tract. Am J Physiol Regul Integr Comp Physiol 280:R1315-R1321.

Fan W, Ellacott KL, Halatchev IG, Takahashi K, Yu P, Cone RD (2004) Cholecystokinin-mediated suppression of feeding involves the brainstem melanocortin system. Nat Neurosci 7:335-336.

Fraser KA, Raizada E, Davison JS (1995) Oral-pharyngeal-esophageal and gastric cues contribute to meal-induced c-fos expression. Am J Physiol 268:R223-R230.

Gee CE, Chen CL, Roberts JL, Thompson R, Watson SJ (1983) Identification of proopiomelanocortin neurones in rat hypothalamus by in situ cDNA-mRNA hybridization. Nature 306:374-376.

Gillespie BR, Burns GA, Ritter RC (2005) NMDA channels control meal size via central vagal afferent terminals. Am J Physiol Regul Integr Comp Physiol 289:R1504-R1511.

Grill HJ, Kaplan JM (2002) The neuroanatomical axis for control of energy balance. Front Neuroendocrinol 23:2-40.

Grill HJ, Ginsberg AB, Seeley RJ, Kaplan JM (1998) Brainstem application of melanocortin receptor ligands produces long-lasting effects on feeding and body weight. J Neurosci 18:10128-10135.

Gulley S, Sharma SK, Moran TH, Sayegh AI (2005) Cholecystokinin-8 increases Fos-like immunoreactivity in the brainstem and myenteric neurons of rats through CCK1 receptors. Peptides 26:1617-1622.

Hornby PJ (2001) Receptors and transmission in the brain-gut axis. II. Excitatory amino acid receptors in the brain-gut axis. Am J Physiol Gastrointest Liver Physiol 280:G1055-G1060.

Jean A (2001) Brainstem control of swallowing: neuronal network and cellular mechanisms. Physiol Rev 81:929-969.

Jin YH, Bailey TW, Li BY, Schild JH, Andresen MC (2004) Purinergic and vanilloid receptor activation releases glutamate from separate cra- nial afferent terminals in nucleus tractus solitarius. J Neurosci 24:4709-4717.

Joseph SA, Pilcher WH, Knigge KM (1985) Anatomy of the corticotropinreleasing factor and opiomelanocortin systems of the brain. Fed Proc 44:100-107.

Katz B (1962) The transmission of impulses from nerve to muscle, and the subcellular unit of synaptic action. Proc R Soc Lond B Biol Sci 155:455-477.

Kishi T, Aschkenasi CJ, Lee CE, Mountjoy KG, Saper CB, Elmquist JK (2003) Expression of melanocortin 4 receptor mRNA in the central nervous system of the rat. J Comp Neurol 457:213-235.

Lin LH, Emson P, Talman WT (2000) Apposition of neuronal elements containing nitric oxide synthase and glutamate in the nucleus of the tractus solitarii of rat: confocal microscopic analsis. Neuroscience 96:341-350.

Liu H, Kishi T, Roseberry AG, Cai X, Lee CE, Montez JM, Friedman JM, Elmquist JK (2003) Transgenic mice expressing green fluorescent protein under the control of the melanocortin-4 receptor promoter. J Neurosci 23:7143-7154.

Martinez-Pena y Valenzuela IM, Browning KN, Travagli RA (2004) Morphological differences between planes of section do not influence the electrophysiological properties of identified rat dorsal motor nucleus of the vagus neurons. Brain Res 1003:54-60.

Meir A, Ginsburg S, Butkevich A, Kachalsky SG, Kaiserman I, Ahdut R, Demirgoren S, Rahamimoff R (1999) Ion channels in presynaptic nerve terminals and control of transmitter release. Physiol Rev 79:1019-1088.

Mifflin SW, Felder RB (1990) Synaptic mechanisms regulating cardiovascular afferent inputs to solitary tract nucleus. Am J Physiol 28:H653-H661.

Palkovits M, Mezey E, Eskay RL (1987) Pro-opiomelanocortin-derived peptides (ACTH/beta-endorphin/alpha-MSH) in brainstem baroreceptor areas of the rat. Brain Res 436:323-338.

Paton JFR, Li Y-W, Deuchars J, Kasparov S (2000) Properties of solitary tract neurons receiving inputs from the sub-diaphragmatic vagus nerve. Neuroscience 95:141-153.

Rinaman L, Verbalis JG, Stricker EM, Hoffman GE (1993) Distribution and neurochemical phenotypes of caudal medullary neurons activated to express cFos following peripheral administration of cholecystokinin. J Comp Neurol 338:475-490.

Rinaman L, Baker EA, Hoffman GE, Stricker EM, Verbalis JG (1998) Medullary c-Fos activation in rats after ingestion of a satiating meal. Am J Physiol 275:R262-R268.

Sayegh AI, Ritter RC (2000) Vagus nerve participates in CCK-induced Fos expression in hind brain but not myenteric plexus. Brain Res 878:155-162.

Schaffar N, Rao H, Kessler JP, Jean A (1997) Immunohistochemical detection of glutamate in rat vagal sensory neurons. Brain Res 778:302-308.

Simasko SM, Ritter RC (2003) Cholecystokinin activates both A- and C-type vagal afferent neurons. Am J Physiol Gastrointest Liver Physiol 285:G1204-G1213.

Smith BN, Dou P, Barber WD, Dudek FE (1998) Vagally evoked synaptic currents in the immature rat nucleus tractus solitarii in an intact in vitro preparation. J Physiol (Lond) 512:149-162.

Sutton GM, Duos B, Patterson LM, Berthoud HR (2005) Melanocortinergic modulation of cholecystokinin-induced suppression of feeding through extracellular signal-regulated kinase signaling in rat solitary nucleus. Endocrinology 146:3739-3747.

Travagli RA, Williams JT (1996) Endogenous monoamines inhibit glutamate transmission in the spinal trigeminal nucleus of the guinea pig. J Physiol (Lond) 491:177-185.

Travagli RA, Hermann GE, Browning KN, Rogers RC (2006) Brainstem circuits regulating gastric function. Annu Rev Physiol 68:279-305.

Treece BR, Ritter RC, Burns GA (2000) Lesions of the dorsal vagal complex abolish increases in meal size induced by NMDA receptor blockade. Brain Res 872:37-43.

Versteeg DH, Van BP, Adan RA, De Wildt DJ (1998) Melanocortins and cardiovascular regulation. Eur J Pharmacol 360:1-14.

Wan S, Coleman FH, Travagli RA (2007) Glucagon-like peptide-1 (GLP-1) excites pancreas-projecting preganglionic vagal motoneurons. Am J Physiol Gastrointest Liver Physiol 292:G1474-G1482.

Williams DL, Kaplan JM, Grill HJ (2000) The role of the dorsal vagal com- 
plex and the vagus nerve in feeding effects of melanocortin-3/4 receptor stimulation. Endocrinology 141:1332-1337.

Willing AE, Berthoud HR (1997) Gastric distension-induced c-fos expression in catecholaminergic neurons of rat dorsal vagal complex. Am J Physiol 272:R59-R67.

Zhang X, Fogel R, Renehan WE (1995) Relationships between the morphology and function of gastric- and intestine-sensitive neurons in the nucleus of the solitary tract. J Comp Neurol 363:37-52.

Zheng H, Kelly L, Patterson LM, Berthoud HR (1999) Effect of brainstem NMDAreceptor blockade by MK-801 on behavioral and Fos responses to vagal satiety signals. Am J Physiol Regul Integr Comp Physiol 277:R1104-R1111.

Zheng H, Patterson C, Berthoud HR (2002a) Behavioral analysis of anorexia produced by hindbrain injections of AMPA receptor antagonist
NBQX in rats. Am J Physiol Regul Integr Comp Physiol 282:R147-R155.

Zheng H, Patterson LM, Berthoud HR (2002b) CART in the dorsal vagal complex: sources of immunoreactivity and effects on Fos expression and food intake. Brain Res 957:298-310.

Zheng H, Patterson LM, Phifer CB, Berthoud HR (2005) Brain stem melanocortinergic modulation of meal size and identification of hypothalamic POMC projections. Am J Physiol Regul Integr Comp Physiol 289:R247-R258.

Zittel TT, Glatzle J, Kreis ME, Starlinger M, Eichner M, Raybould HE, Becker HD, Jehle EC (1999) C-fos protein expression in the nucleus of the solitary tract correlates with cholecystokinin dose injected and food intake in rats. Brain Res 846:1-11. 